\title{
Unsaturated Lipid Accelerates Formation of Oligomeric $\beta$-Sheet Structure of GP41 Fusion Peptide in Model Cell Membrane
}

\author{
Wenting Wang, Junjun Tan, Shuji Ye* \\ Hefei National Laboratory for Physical Sciences at the Microscale, and Department of Chemical \\ Physics, University of Science and Technology of China, Hefei, Anhui 230026, China
}

1. Schematic structures of $\beta$-strand, $\beta$-sheet and $\beta$-turn

Structure of a $\beta$ Strand:

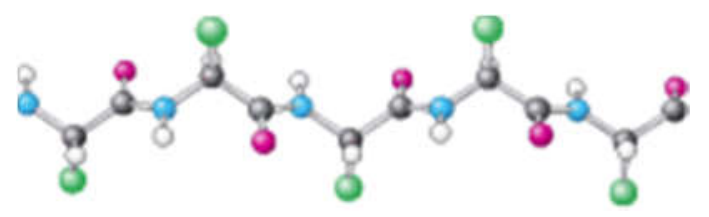

An antiparallel $\beta$ Sheet:

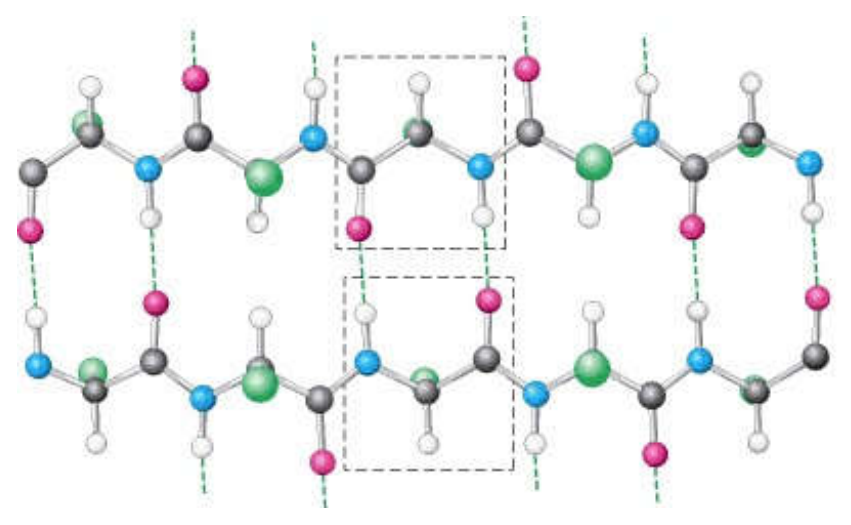


A parallel $\beta$ Sheet:

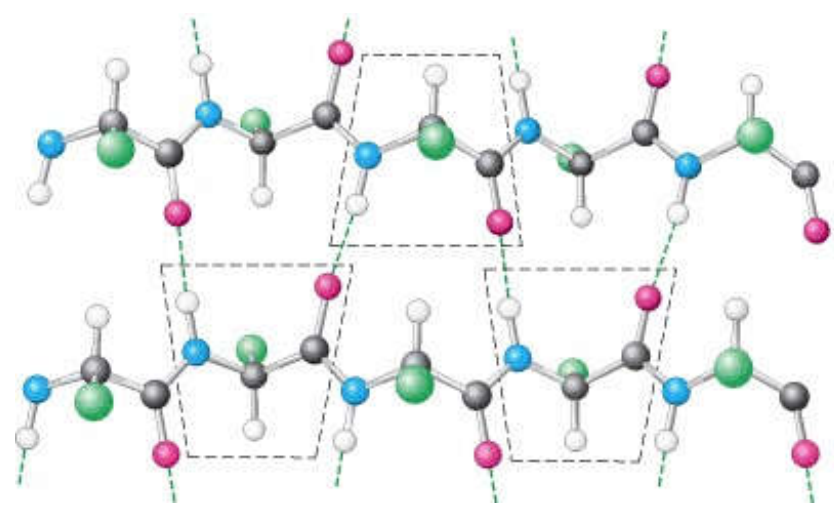

Structure of a $\beta$-turn:

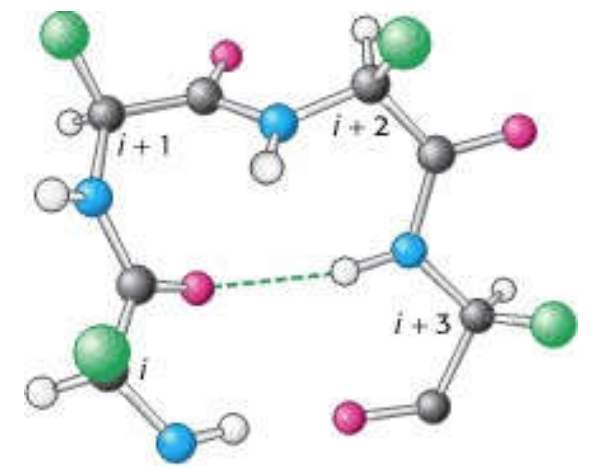

Figure S1. Schematic structures of $\beta$ - strand, $\beta$-sheet and $\beta$-turn. ${ }^{1}$ Reproduced with permission from Biochemistry. 5th edition. W H Freeman: New York, 2002. Copyright (C 2002, W. H. Freeman and Company.

\section{The structures of lipids}

POPG:<smiles>CCCCCCCC/C=C\CCCCCCCCCCC(=O)OC[C@H](COP(=O)([OH2+])OCC(O)CO)OC(=O)CCCCCCCCCCCC</smiles>

DLPG:<smiles>CCCCCCCCCCCC(=O)OC[C@H](COP(=O)([OH2+])OCC(O)CO)OC(=O)CCCCCCCCCC</smiles> 
<smiles>CCCCCCCCCCCCCCCCCCCC(=O)OC[C@H](COP(=O)([OH2+])OCC(O)CO)OC(=O)CCCCCCCC</smiles>

DPPG:<smiles>CCCCCCCCCCCCCCCC(=O)OC[C@H](COP(=O)([OH2+])OCC(O)CO)OC(=O)CCCCCCCCCCCCC</smiles>

Figure S2. The molecular structures of the used lipids.

\section{The possibility of the $\chi^{(3)}$ contribution to SFG signals of peptide molecules at negative}

\section{PG lipid bilayer/water interface}

At a charged surface, a surface potential $(\Phi(0))$ may lead to the third-order contribution to the SFG signals. ${ }^{2-5}$ The measured SFG intensity is expressed by eqn. S1..$^{2-5}$

$I_{S F G} \propto\left|\chi_{N R}^{(2)}+\sum_{v=1}^{n} \chi_{R e s, v}^{(2)} e^{i \gamma_{v}}+\frac{\kappa}{\sqrt{\kappa^{2}+\left(\Delta k_{z}\right)^{2}}} e^{i \arctan \left(\Delta k_{z} / \kappa\right)} \Phi(0) \chi^{(3)}\right|^{2}$

where the first two terms are the nonresonant and resonant second-order susceptibility and the third term is the third-order contribution. The third-order contribution is given by the inverse Debye screening length, $\kappa$, the inverse of the coherence length of the SFG process, $\Delta k_{z}$, and the surface potential, $\Phi(0)$, the third-order susceptibility $\left(\chi^{(3)}\right) \cdot{ }^{2-5}$ In our experimental conditions, $\kappa=1 /(961$ $\mathrm{nm})$ and $\Delta k_{z}=\sim 1 /(36 \mathrm{~nm})$ in the amide I band region. The calculated $\frac{\kappa}{\sqrt{\kappa^{2}+\left(\Delta k_{\mathrm{z}}\right)^{2}}}=0.037$.

Although the third-order $\chi^{(3)}$ response can make a significant contribution to the water SFG signals at the charge surfaces, here we argue that the $\chi^{(3)}$ contribution to the SFG signals of interfacial peptides is essentially neglected. First, being different from the case of the interfacial water which has the bulk molecules of $55.56 \mathrm{M}$, the bulk concentration of FP23 at the subphase of the 
bilayer is less than $1.5 \times 10^{-5} \mathrm{M}$ and is about $2.7 \times 10^{-7}$ time of the water. Secondly, in term of the results of the interaction between FP23 and PC lipid bilayer, the surface potential might not be able to polarize and align the peptide molecules in the solution phases. According to reference 2, the surface potentials are considerable even when a PC head group is present. If the $\chi^{(3)}$ contribution is detectable in our study, we should observe the FP23 SFG signals when we inject FP23 into PC lipid bilayer. However, as shown in Figure S3, we do not observe the FP23 SFG signals after we inject $15 \mu \mathrm{L}$ FP23 solution into the subphase of POPC bilayer (with a FP23 concentration of 15 $\mu \mathrm{g} / \mathrm{mL}$ in the subphase of bilayer), indicating FP23 molecules do not interact with POPC bilayer and they might adopt a random orientation in the bulk phase. In Figure S3, a broad peak is observed in the pure POPC bilayer. This broad peak comes from the water. After we inject $15 \mu \mathrm{L}$ FP23 solution, the intensity of the broad band decreases about $6 \%$. In contrast, strong amide I signals are observed after injecting $15 \mu \mathrm{L}$ FP23 solution into POPG bilayer (with a FP23 concentration of 15 $\mu \mathrm{g} / \mathrm{mL}$ in the subphase of bilayer).

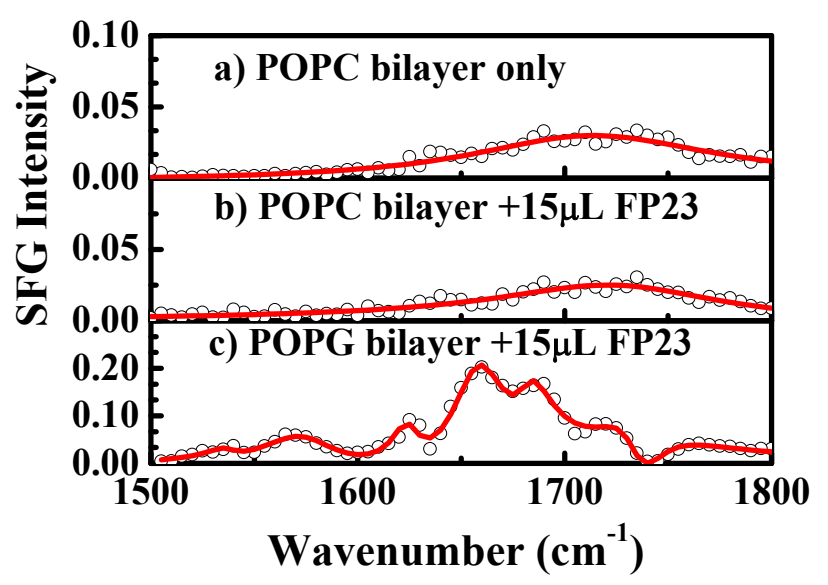

Figure S3. The ssp SFG spectra in the frequency region of $1500-1800 \mathrm{~cm}^{-1}$. a) The signals of POPC bilayer without injecting FP23. b) After $15 \mu \mathrm{L} \mathrm{FP23} \mathrm{interacts} \mathrm{with} \mathrm{POPC} \mathrm{bilayer} \mathrm{for} 3 \mathrm{~h}$. c) After 
$15 \mu \mathrm{L}$ FP23 interacts with POPG bilayer for $3 \mathrm{~h}$. The FP23 concentrations in the subphase of POPC and POPG bilayer both are $15 \mu \mathrm{g} / \mathrm{mL}$.

Thirdly, the interaction between the positive peptide molecules and the negative lipid bilayer can effectively neutralize the surfaces and reduce the interfacial potential, which can be confirmed by the ssp SFG signals from the interfacial water. As shown in Figure S4, very strong SFG signals from the water molecules are observed at the DMPG/water interface due to the $\chi^{(3)}$ contribution (Figure S4a). However, after $15 \mu \mathrm{L} \mathrm{FP23} \mathrm{solution} \mathrm{is} \mathrm{injected} \mathrm{into} \mathrm{the} \mathrm{subphase} \mathrm{of} \mathrm{DMPG} \mathrm{lipid}$ bilayer, the ssp SFG intensity of the $\sim 3440 \mathrm{~cm}^{-1}$ peak from the water molecules is close to 0 (Figure $\mathrm{S} 4 \mathrm{~b}$ ), indicating the disappearance of the $\chi^{(3)}$ contribution.

a)

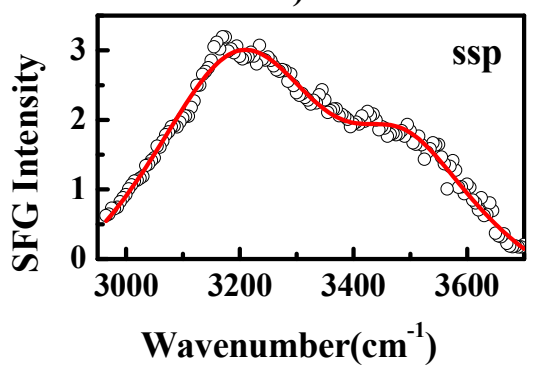

b)

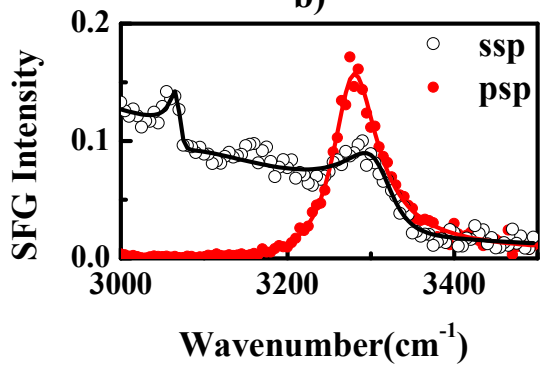

Figure S4. a) The ssp SFG spectra of the water at DMPG lipid bilayer/water interface. b) The SFG spectra in the frequency range in $3000-3500 \mathrm{~cm}^{-1}$ region after $15 \mu \mathrm{L}$ FP23 interacts with DMPG lipid bilayer for $3 \mathrm{~h}$ (with a FP23 concentration of $15 \mu \mathrm{g} / \mathrm{mL}$ in the subphase of bilayer).

Fourthly, Koelsch and Chen, et al. have considered the possibility that the surface charge may cause $\chi^{(3)}$ to contribute to SFG signals. ${ }^{6,7}$ They found that the resonant third-order hyperpolarizability tensor elements are some 10 orders of magnitude smaller than the second-order tensor elements. ${ }^{6,7}$ If we considered an interfacial electrostatic field of $1 \times 10^{8} \mathrm{~V} / \mathrm{m}$ and a low concentration of bulk peptide molecules, the $\chi^{(3)}$ contribution is at least two order of magnitude smaller than the $\chi^{(2)}$ contribution. Therefore, the $\chi^{(3)}$ contribution is essentially neglected in our study. 


\section{The interaction of $15 \mu \mathrm{L}$ FP23 solution and POPG lipid bilayer}
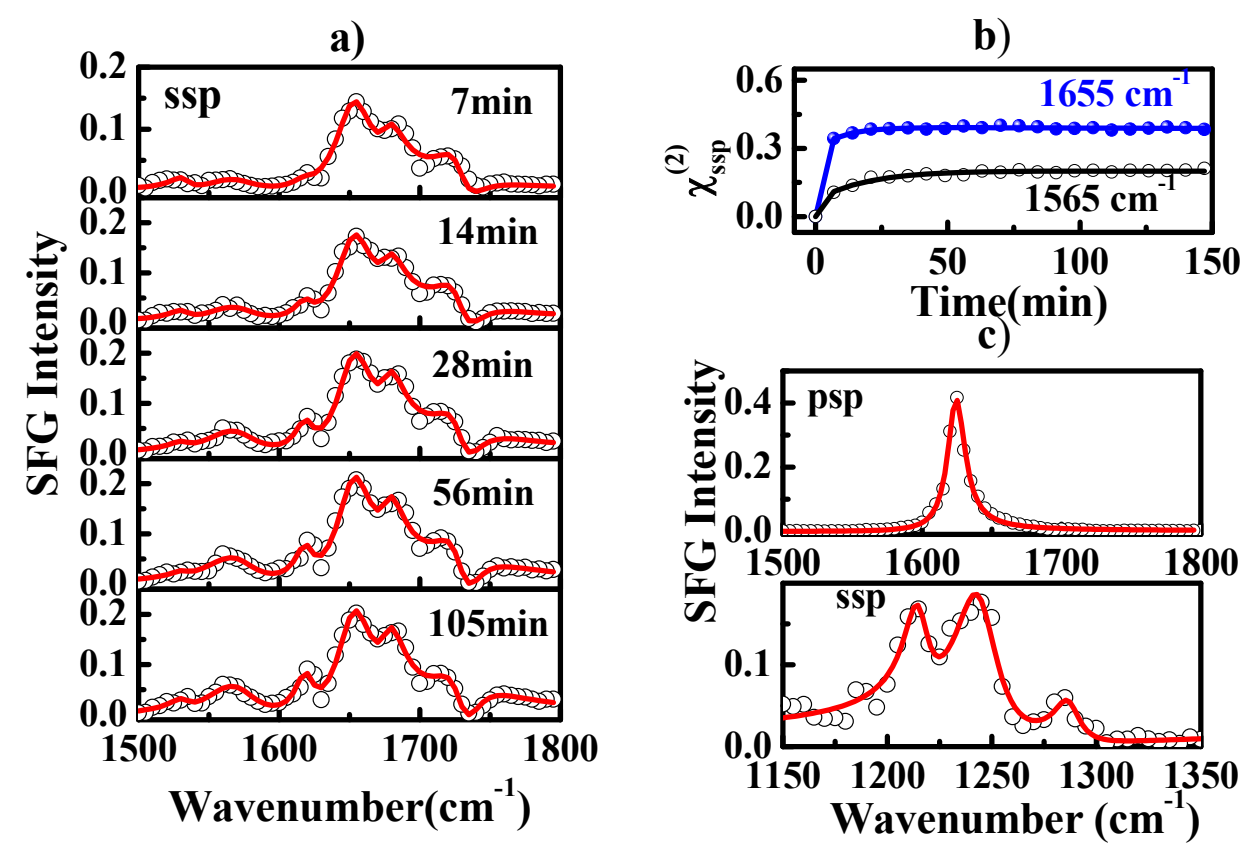

Figure S5. The SFG spectra of FP23 after injecting $15 \mu \mathrm{L}$ FP23 $(2 \mathrm{mg} / \mathrm{mL})$ into the subphase (2.0 $\mathrm{mL}$ ) of POPG bilayer at $\mathrm{t}=0 \mathrm{~min}$ (with a FP23 concentration of $15 \mu \mathrm{g} / \mathrm{mL}$ in the subphase of bilayer).

a) The ssp SFG spectra in the frequency region of $1500-1800 \mathrm{~cm}^{-1}$ collected at different time interval. b) The intensity of the $1655 \mathrm{~cm}^{-1}$ peak changes with time. c) The psp amide I and ssp amide III spectra of FP23 collected at $3 \mathrm{~h}$.

Figure S5 shows the results for the interaction between $15 \mu \mathrm{L} \mathrm{FP} 23(2 \mathrm{mg} / \mathrm{mL})$ and POPG lipid bilayers (with a FP23 concentration of $15 \mu \mathrm{g} / \mathrm{mL}$ in the subphase of bilayer). Different from the case of injection of $5 \mu \mathrm{L}$, besides the peaks at $\sim 1655, \sim 1680$, and $\sim 1715 \mathrm{~cm}^{-1}$, a new peak at $1565 \mathrm{~cm}^{-1}$ appears at $\mathrm{t} \geq 7 \mathrm{~min}$ in the ssp spectra (Figure S5a). The $1565 \mathrm{~cm}^{-1}$ peak arises from the amide II band. The appearance of the $\sim 1565 \mathrm{~cm}^{-1}$ peak implies the formation of oligomeric $\beta$-sheet structure. This amide II intensity is weaker than the case of injecting $30 \mu \mathrm{L}$ (Figure 2). The psp 
amide I spectrum is also dominated by a strong resonance peak $\left(\sim 1625 \mathrm{~cm}^{-1}\right)$, indicating the formation of $\beta$-sheet structure. The ssp amide III spectrum displays three peaks at $1215 \mathrm{~cm}^{-1}, 1245$ $\mathrm{cm}^{-1}$, and $1280 \mathrm{~cm}^{-1}$ (Figure S5c). The intensity ratio (at $\mathrm{t} \sim 3 \mathrm{~h}$ ) between the $\sim 1565 \mathrm{~cm}^{-1}$ peak in the ssp spectrum and the $1625 \mathrm{~cm}^{-1}$ peak in the psp spectrum $\left(\chi_{\text {ssp }}^{(2)}(\mathrm{Am} \mathrm{II}) / \chi_{\mathrm{psp}}^{(2)}(\mathrm{Am} \mathrm{I})\right)$ increases as the injected amount of FP23 increases (Figure S6), indicating that the concentration of FP23 promotes the formation of oligomeric $\beta$-sheet structure.

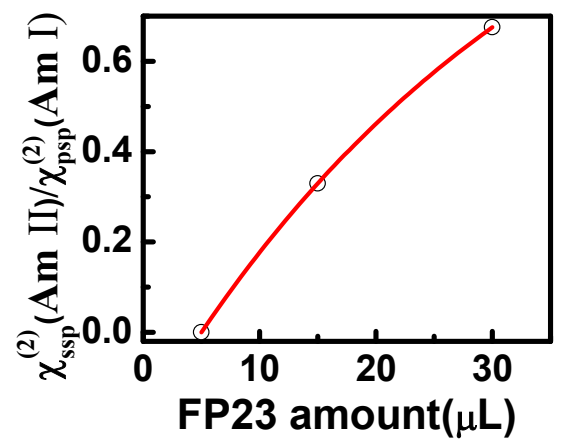

Figure S6. The intensity ratio (at $\mathrm{t} \sim 3 \mathrm{~h}$ ) between the $\sim 1565 \mathrm{~cm}^{-1}$ peak in the ssp spectrum and the $1625 \mathrm{~cm}^{-1}$ peak in the psp spectrum $\left(\chi_{\text {ssp }}^{(2)}(\mathrm{Am} \mathrm{II}) / \chi_{\mathrm{psp}}^{(2)}(\mathrm{Am} \mathrm{I})\right)$ is plotted against the injected amount of FP23.

\section{The interaction of $15 \mu \mathrm{L}$ FP23 solution and saturated lipid bilayer}
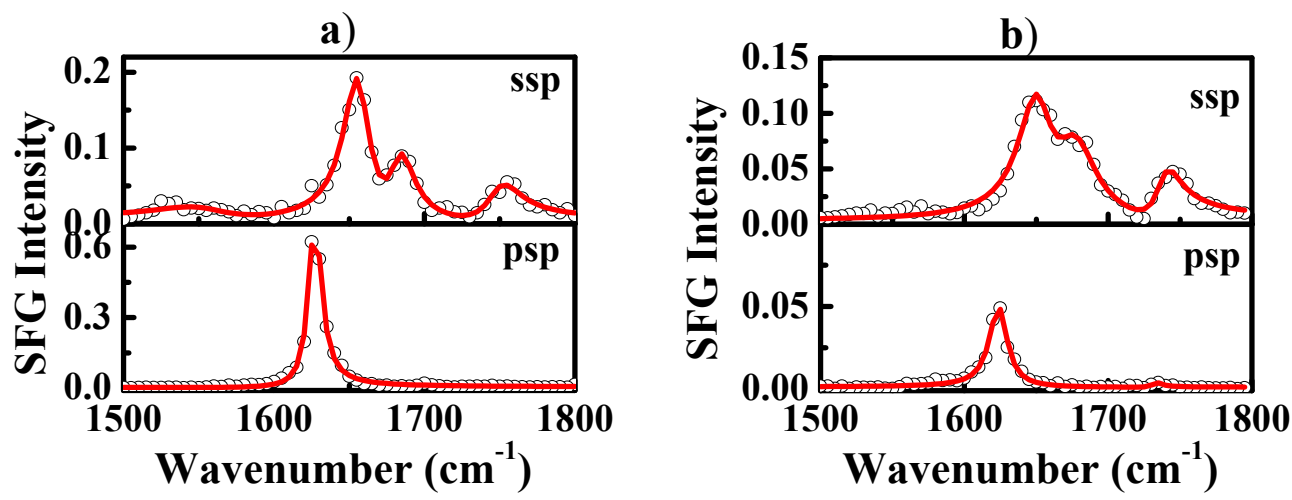
Figure S7. The ssp and psp amide I SFG spectra of FP23 collected at $\mathrm{t}=5 \mathrm{~h}$ after injecting FP23 (2 $\mathrm{mg} / \mathrm{mL})$ into the subphase $(2.0 \mathrm{~mL})$ of lipid bilayer at $\mathrm{t}=0$. a) $15 \mu \mathrm{L}$ FP23 into DMPG lipid bilayer.

b) $15 \mu \mathrm{L}$ FP23 into DPPG lipid bilayer. The FP23 concentration in the subphase of bilayers is $15 \mu \mathrm{g} / \mathrm{mL}$.

Figure S7 shows the ssp and psp SFG spectra for the result of interaction between FP23 (2 $\mathrm{mg} / \mathrm{mL}$ ) and saturated lipid DMPG and DPPG bilayers. It is found that the spectral features of FP23 at these saturated lipid bilayers are similar to the case of low -amount of FP23 at POPG bilayer (Figure 1). Namely, FP23 adopts a monomeric $\beta$-sheet conformation, rather than oligomeric $\beta$-sheet structure at DMPG and DPPG lipid bilayers. The results indicate that the FP23 fusion domain has significant structural plasticity, and is influenced critically by the lipid environment and peptide concentration. Saturated lipid can retard the formation of multistranded $\beta$-sheet structure of FP23.

\section{The fitting parameters of the peaks shown in Figure 4}

Table S1. The fitting parameters of the peaks shown in Figure 4.

\begin{tabular}{cccccccc}
\hline \multirow{3}{*}{ Structure } & \multicolumn{2}{c}{$\mathrm{H}_{2} \mathrm{O}$} & & \multicolumn{3}{c}{$\mathrm{D}_{2} \mathrm{O}$} & Ratio \\
& $\mathrm{A}_{v}$ & $\omega_{v}\left(\mathrm{~cm}^{-1}\right)$ & $\Gamma_{v}\left(\mathrm{~cm}^{-1}\right)$ & $\mathrm{A}_{v}$ & $\omega_{v}\left(\mathrm{~cm}^{-1}\right)$ & $\Gamma_{v}\left(\mathrm{~cm}^{-1}\right)$ & \\
\hline$\beta$-sheet & 3.63 & 1215.4 & 12.0 & 3.57 & 1217.9 & 12.0 & 0.98 \\
unordered & 12.40 & 1247.5 & 20.0 & 10.17 & 1251.4 & 20.0 & 0.82 \\
$\alpha$-helix & 2.22 & 1280 & 8.0 & 0.34 & 1280 & 8.0 & 0.15 \\
\hline
\end{tabular}

\section{References}

(1) Berg, J.M.; Tymoczko, J.L.; Stryer, L. Biochemistry. 5th edition. W H Freeman: New York, 2002. 
(2) Dogangun, M.; Ohno, P.E.; Liang, D.; McGeachy, A.C.; Bé, A.G.; Dalchand, N.; Li, T.; Cui, Q.; Geiger, F.M. Hydrogen Bond Networks near Supported Lipid Bilayers from Vibrational Sum Frequency Generation Experiments and Atomistic Simulations. J. Phys. Chem. B 2018, $122,4870-4879$.

(3) Reddy, S. K.; Raphael Thiraux, R.; Rudd, B.A.W.; Lin, L.; Adel, T.; Joutsuka, T.; Geiger, F.M.; Allen, H.C.; Morita, A.; Paesani, F. Bulk Contributions Modulate the Sum-Frequency Generation Spectra of Interfacial Water on Model Sea-Spray Aerosols. Chem 2018, 4, 1629-1644.

(4) Ohno, P.E.; Wang, H.F.; Skinner, J.; Paesani, F.; Geiger, F.M. Second-Order Vibrational Lineshapes from the Air/Water Interface. J. Phys. Chem. A 2018, 122, 4457-4464.

(5) Ohno, P.E.; Wang, H.F.; Geiger, F.M. Second-Order Spectral Lineshapes from Charged Interfaces. Nat. Commun. 2017, 8, 1032.

(6) Koelsch, P.; Muglali, M.I.; Rohwerder, M.; Erbe, A. Third-Order Effects in Resonant SumFrequency-Generation Signals at Electrified Metal/Liquid Interfaces. J. Opt. Soc. Am. B 2013, $30,219-223$.

(7) Chen, X.; Wang, J.; Paszti, Z.; Wang, F.; Schrauben, J. N.; Tarabara, V. V.; Schmaier, A. H.; Chen, Z. Ordered Adsorption of Coagulation Factor XII on Negatively Charged Polymer Surfaces Probed by Sum Frequency Generation Vibrational Spectroscopy. Anal. Bioanal. Chem. 2007, 388, 65-72. 